\title{
Use frequency of traditional Chinese medicine in Taiwan Fang-Pey Chen ${ }^{1,2}$, Tzeng-Ji Chen ${ }^{2,3}$, Yen-Ying Kung ${ }^{1,2}$, Yu-Chun Chen ${ }^{2,3}$, Li- Fang Chou ${ }^{4}$, Fan-Jou Chen ${ }^{5}$ and Shinn-Jang Hwang*2,3,1
}

\begin{abstract}
Address: ${ }^{1}$ Center for Traditional Medicine, Taipei Veterans General Hospital, No.201, Section 2, Shih-Pai Road, Taipei 112 Taiwan, ${ }^{2}$ National YangMing University School of Medicine, No.155, Section 2, Linong Street, Peitou District, Taipei 112, Taiwan, ${ }^{3}$ Department of Family Medicine, Taipei Veterans General Hospital, No.201, Section 2, Shih-Pai Road, Taipei 112 Taiwan, ${ }^{4}$ Department of Public Finance, National ChengChi University, No. 64, Section 2, Zhinan Road, Wenshan District, Taipei 116 Taiwan and ${ }^{5}$ Graduate Institute of Integration Chinese and Western Medicine, Chinese Medical University, No. 91, Hsueh-Shih Road, Taichung 404 Taiwan
\end{abstract}

Email: Fang-Pey Chen - fpchen@vghtpe.gov.tw; Tzeng-Ji Chen - tjchen@vghtpe.gov.tw; Yen-Ying Kung - yyk@vghtpe.gov.tw; YuChun Chen - cbrain@self.twmail.cc; Li-Fang Chou - lifang@nccu.edu.tw; Fan-Jou Chen - fjchen@mail.cmu.edu.tw; Shinn-

Jang Hwang* - sjhwang@vghtpe.gov.tw

* Corresponding author

Published: 23 February 2007

BMC Health Services Research 2007, 7:26 doi:10.1 186/1472-6963-7-26
Received: 4 August 2006

Accepted: 23 February 2007

This article is available from: http://www.biomedcentral.com/1472-6963/7/26

(C) 2007 Chen et al; licensee BioMed Central Ltd.

This is an Open Access article distributed under the terms of the Creative Commons Attribution License (http://creativecommons.org/licenses/by/2.0), which permits unrestricted use, distribution, and reproduction in any medium, provided the original work is properly cited.

\begin{abstract}
Background: Use of Traditional Chinese medicine (TCM), an important category of complementary and alternative medicine (CAM), has increased substantially in Western countries during the past decade. Use of TCM is also widespread in the Chinese population. However, few informative data have been obtained to date by large-scale investigations of TCM use in the Chinese population. This study was aimed at elucidating the demographics and patterns of TCM use in Taiwan.

Methods: We employed the complete datasets of TCM outpatient reimbursement claims from 1996 to 200I, including the use of Chinese herbal remedies, acupuncture and traumatology manipulative therapy, to analyse use frequencies, the characteristics of TCM users, and the disease categories that were treated by TCM in Taiwan.

Results: At the end of 200I, 6, I42,829 (28.4\%) among the 2I,653,555 valid beneficiaries of the National Health Insurance in Taiwan had used TCM during the year. However, 13,536,266 subjects (62.5\%) had used TCM at least once during the whole 6-year period from 1996 to 200 I, with a total of $156,224,266$ visits (mean II.5 visits per user). The mean number of TCM users per annum was 5,733,602, with a mean increment of I,67I,476 (29.2\%) of new users yearly. Among TCM users, female was higher than male (female:male $=1.13: 1$ ), and the age distribution displayed a peak at around the 30s, followed by the $20 \mathrm{~s}$ and $40 \mathrm{~s}$. Chinese herbal remedies $(85.9 \%)$ were the most common TCM modality used by this population, followed by acupuncture (1I.0\%) and traumatology manipulative therapies (3.1\%). Private TCM clinics provided most of the TCM care (82.6\%), followed by private TCM hospitals (12.0\%). The top ten major disease categories for TCM visits were diseases of the respiratory system, musculoskeletal system and connective tissue; symptoms, signs and ill-defined conditions; injury and poisoning; diseases of the digestive system, genitourinary system, skin and subcutaneous tissue, nervous system and sense organs, circulatory and endocrine system; nutritional and metabolic diseases; and immunological disorders.

Conclusion: TCM was popular among the Chinese population in Taiwan during the period studied. More than $60 \%$ of all subjects had used TCM during the 6 -year interval. TCM was widely used by the Chinese population to treat problems and diseases of major human organ systems recognised by western medicine. This study provides information about the use frequencies of TCM and the disease categories treated by TCM, which should be useful for health policy makers and for those considering the integration of TCM and Western medicine.
\end{abstract}




\section{Background}

Interest in complementary and alternative medicine (CAM) has increased substantially in western countries during the past decade [1-4]. Patients and their families seem to have sought their health practitioners' opinions about various CAM modalities more frequently $[1,2]$. Recent studies have demonstrated dramatic increases in the use of, and expenditure on, CAM in the United States, Canada, Australia and European countries [5-8]. However, most of the prevalent studies of CAM use were based primarily on questionnaire surveys, telephone interviews or collecting data from insurance claims, and the sample sizes generally were limited.

Traditional Chinese medicine (TCM) is an important category of CAM in Western opinion [9]. Current TCM practices can be traced back more than 2000 years. The concepts of Ying-Yang, Five Elements, Meridians, and the use of many herbal remedies, originated from ancient China $[10,11]$. TCM is still commonly used by the Chinese $[4,12,13]$. In Taiwan, not until the 1980 s did several researchers start to research issues relevant to TCM, using sampling surveys or studies with small sample sizes [1420]. To date, there has been no large-scale investigation of the use of TCM among Chinese people worldwide.

In Taiwan, the National Health Insurance (NHI) program was started in 1995 and covers nearly all inhabitants (21,653,555 beneficiaries at the end of 2001) [21-23]. The use of TCM has been reimbursed by the NHI since 1996 . People in Taiwan are free to choose Western medicine or TCM, and are allowed to visit either public or private medical facilities. Because all claims data are available to researches in electronic form, we could conduct a study of TCM use among the Chinese population in Taiwan.

The aim of this study was to conduct a nation-wide survey in order to establish the frequency of TCM use, the characteristics of TCM users, and the medical conditions for which Taiwanese people most commonly use TCM, by analyzing the NHI claims data from 1996 to 2001. TCM provided by the NHI included Chinese herbal remedies, acupuncture and traumatology manipulative therapy [24].

\section{Methods \\ Data Sources}

The NHI program was initiated in Taiwan since 1995 and covers nearly all inhabitants $(21,653,555$ beneficiaries at the end of 2001, equivalent to a coverage rate of $96.6 \%$ ). In 1999, the Bureau of NHI began to release all claims data in electronic form to the public under the National Health Insurance Research Database (NHIRD) project. The structure of the claim files is described in detail on the NHIRD website and in other publications $[19,25]$.
We obtained the complete TCM claim datasets (CM_CD199601.DAT to CM_CD200112.DAT, 72 files) from the NHIRD in Taipei in November 2002. The datasets contained only the visit files, including dates, medical care facilities and specialties, patients' genders, dates of birth, and the three major diagnoses coded in the International Classification of Disease, $9^{\text {th }}$ Revision, Clinical Modification (ICD-9-CM) format [26-28]. To protect privacy, the data on patient identities and institutions had been scrambled cryptographically.

These visit files represented all the TCM outpatient activities within the NHI from 1996 to 2001. Insurance benefits were available for TCM that included Chinese herbal remedies, acupuncture and traumatology manipulative therapy, especially for joint dislocation. In Taiwan, TCM is reimbursed by NHI only in ambulatory clinics, not for inpatient care. In addition, only licensed TCM physicians qualify for reimbursement from the NHI. At the end of 2001, there were 2 public TCM hospitals, 42 private TCM hospitals and 2,544 private TCM clinics providing TCM ambulatory visits [22].

To calculate the numbers of valid beneficiaries in the study period, the beneficiaries' registry files (ID2002_1.DAT to ID2002_8.DAT) were also obtained.

\section{Study Design}

Although the concept of disease entities in TCM is quite different from that in Western medicine, TCM physicians are requested to follow the standard diagnoses according to the ICD-9-CM coding system when claiming reimbursement. Common diagnostic groups for TCM visits were categorized according to the reclassification of primary ICD-9-CM codes for use in the National Ambulatory Medical Care Survey and National Hospital Ambulatory Medical Care Survey data in the United States [29].

To calculate patients' ages in relation to the 6-year use frequency of TCM from 1996 to 2001, December 31, 2001 was taken as the index of subtrahend. The denominator was the number of people who were insured during this 6-year period.

In order to compare the average numbers of visits between TCM and Western (allopathic) medicine, we also obtained the total number of ambulatory visits to Western medicine from the website of Department of Health, Taiwan [22]. In addition, we obtained the sampling claim datasets for ambulatory care visits at Western medicine clinics (S_CD 1996 to S_CD2001) in order to compare the top ten disease categories between TCM and Western medicine visits. The Western medicine files to be sampled were extracted from the complete outpatient claims (excluding dental and TCM services), using a sampling 
ratio of $0.2 \%$. The sampling was random and visit-based but was separated monthly to eliminate possible seasonal variations. According to the NHIRD, these sampled files were representative of all utilisation within the NHI in Taiwan.

\section{Statistical Analysis}

Microsoft SQL Server 2000 (MicroSoft Corp., Redmond, WA USA) was the main software used for data linkage and processing. Descriptive data, including frequencies, percentage and means, are presented.

\section{Results}

Among the 21,653,555 valid beneficiaries of the NHI program at the end of 2001, 16,142,829 (28.4\%) had used TCM during the year, but 13,536,266 (62.5\%) had used TCM at least once during the whole 6-year period from 1996 to 2001, with a total of 156,224,266 visits (mean 11.5 visits per user). The annual number and percentage of TCM users steadily increased from 1996 to 2001 (Table 1). However, the annual number of TCM visits remained stationary from 1998 to 2001. There was a mean of $5,733,602$ annual TCM users (ranging from $25.8 \%$ of the valid beneficiaries within NHI in 1996 to $28.4 \%$ in 2001) with a mean increment of 1,671,476 (29.2\%) of new users yearly. Among TCM users, female was higher than male with a female:male ratio of 1.13:1. The age distribution of the TCM users peaked in the 30s, followed by the 20s and 40s (Table 2), while the age distribution for visit counts showed a peak in the 30 s followed by the 40 s and 20s. Adjusted for the total population in each 10-year age group, the use frequency of TCM still showed a peak in the 30 s, followed by the 20 s and 60s. When the details of each age group were investigated, it was found that more than $50 \%$ of patients used TCM if they were over 10 years old.

Among the 13,536,266 subjects who experienced TCM during the 6-year period, 4,832,233 (35.7\%) used TCM only in one year, $3,065,072(22.6 \%)$ in two separate years, $2,106,523(15.6 \%)$ in three separate years, $1,495,694$ $(11.0 \%)$ in 4 separate years, $1,083,577$ (8.0\%) in 5 separate years and $953,167(7.0 \%)$ in all six years. As to the visit counts during this 6 -year period, $19.4 \%$ of subjects used TCM only once, $47.8 \%$ used it more than 6 times (once per year on average) and 2.3\% used it more than 72 times (once per month on average) (Figure 1).

Chinese herbal remedies $(85.9 \%)$ were the most common TCM modality, followed by acupuncture (11.0\%) and traumatology manipulative therapies (3.1\%). Most of the TCM visits identified in the study were performed in private TCM clinics $(82.6 \%)$, followed by private TCM hospitals $(10.7 \%)$, others $(4.7 \%$, mostly Western medicine hospitals with TCM sections) and public TCM hospitals $(0.7 \%)$. Visits to private TCM hospitals decreased yearly, while visits to private TCM clinics, public TCM hospitals and others increased (Table 3).

Among the 156,224,266 TCM visits, 150,365,543 (96.2\%) had one clinical diagnosis, 4,955,213 (3.2\%) had two diagnoses and 881,438 (0.6\%) had three diagnoses according to the ICD-9-CM coding system. The top ten diseases for TCM visits were diseases of respiratory system; diseases of the musculoskeletal system and connective tissue; symptoms, signs and ill-defined conditions; injury and poisoning; diseases of the digestive system, the genitourinary system, the skin and subcutaneous tissue, the nervous system and sense organs, the circulatory and endocrine system; nutritional and metabolic diseases; and immunological disorders (Table 4). Common problems and diseases of major human organ systems recognised in Western medicine were all ranked in the top 41 diagnostic groups for TCM visits (Table 5). They included three disease groups relating only to females: disorders of menstration and abnormal bleeding (ICD code: 626.4), noninflammatory disorders of female genital organs (ICD code: 625.5$)$ and inflammatory disorders of female pelvic organs (ICD code 614.9). Thus, people with diseases commonly seen in Western medicine used TCM.

Furthermore, we analyzed the percentage distribution of major disease categories for TCM visits by age (Table 6). The results show that for respiratory system diseases and injuries, the percentages of visits were higher in the younger groups and decreased with age. In contrast, for the categories of symptoms, signs and ill-defined conditions, musculoskeletal system, nervous system, circulatory system, endocrine and metabolic diseases, mental disorders and neoplasms, the percentages of visits were lower in the younger groups and increased with age. We found no significant differences between males and females in the percentage distributions of the commonest disease categories for TCM visits (Table 7). However, female subjects visited TCM for diseases of the genitourinary system (10.6\%) more frequently than males (2.2\%). We also compared the percentage distribution of major disease categories for TCM visits among different locations and the results revealed that the categories of injury, poisoning and symptoms, signs and ill-defined conditions were more commonly seen in clinics than in hospitals (Table 8).

\section{Discussion}

To the best of our knowledge, this study is the first extensive survey of TCM use in Chinese society. Only with the aid of a computerised insurance reimbursement database could such a large-scale TCM utilization study feasibly be analysed. Previous studies from western countries on the frequency and characteristics of CAM/TCM use have mainly consisted of surveys of clinic attendees, telephone 
Table I: Patient use and visit counts of traditional Chinese medicine (TCM) within National Health Insurance (NHI) from I996 to 200 I in Taiwan

\begin{tabular}{|c|c|c|c|c|c|c|}
\hline \multirow[t]{2}{*}{ Year } & \multirow{2}{*}{$\begin{array}{c}\text { Valid beneficiaries } \\
\text { within } \mathrm{NHI}\end{array}$} & \multicolumn{3}{|c|}{ Subjects using TCM } & \multirow{2}{*}{$\begin{array}{c}\text { New patients } \\
(\%)\end{array}$} & \multirow{2}{*}{ Total visits } \\
\hline & & Total No. (\%)* & Female & Male & & \\
\hline 1996 & $20,04 I, 488$ & $5,178,887$ a $(25.8 \%)$ & $2,884,798(55.7 \%)$ & $2,276,795(44.0 \%)$ & $5,178,887$ a & $24,094,552$ \\
\hline 1997 & $20,492,317$ & $5,444,532(26.6 \%)$ & $3,025,170(55.6 \%)$ & $2,400,105(44.1 \%)$ & $2,506,004 \mathrm{~b}(46.0 \%)$ & $25,170,073$ \\
\hline 1998 & $20,757,185$ & $5,633,794(27.1 \%)$ & $3,|35,70|(55.7 \%)$ & $2,466,698(43.8 \%)$ & $1,862,599$ c (33.1\%) & $26,641,926$ \\
\hline 1999 & $21,089,859$ & $5,937,644(28.2 \%)$ & $3,305,115(55.7 \%)$ & $2,605,236(43.9 \%)$ & $1,556,868 \mathrm{~d}(26.2 \%)$ & $27,398,595$ \\
\hline 2000 & $21,400,826$ & $6,063,923(28.3 \%)$ & $3,384,892(55.8 \%)$ & $2,642,655(43.6 \%)$ & $1,314,192$ e (2I.7\%) & $26,426,753$ \\
\hline 2001 & $21,653,555$ & $6,142,829(28.4 \%)$ & $3,420,592(55.7 \%)$ & $2,672,785(43.5 \%)$ & $1,117,716 \mathrm{f}(18.2 \%)$ & $26,492,367$ \\
\hline Total & & & $7,097,695 \ddagger(52.4 \%)$ & $6,292,508 \ddagger(46.5 \%)$ & $13,536,266 \dagger(a+b+c+d+e+f)$ & $156,224,266$ \\
\hline
\end{tabular}

* Number within parenthesis indicates percentage of subjects using TCM among valid beneficiaries within NHI in that year; $\dagger \mid 46,063$ people whose genders were not recorded; $\neq$ Female:male = I.13:I. New patients indicate people who used NHI-covered TCM for the first time.

interviews, written surveys, household interviews, and hospital and private clinic surveys; and the sample sizes have been limited. In addition, the use of CAM/TCM in western countries is usually not covered by insurance [30]. Thus, the survey results might be affected by the socio-economic status of the subjects [31]. Fortunately, TCM is reimbursed by NHI in Taiwan, so our study would appear to be less biased.

The use of CAM/TCM in western countries has increased dramatically in recent decades [1,5-8], [32-34]. It goes without saying that TCM has been commonly used in Asian countries, especially in the Chinese population, for centuries [17-19,35-37]. Owing to the different definitions of CAM, the types of CAM surveyed, survey methodologies and types of CAM reimbursed by insurance, it is difficult to compare the use frequency of CAM/TCM among countries $[38,39]$. According to our results, there was a steady increase in the annual number of TCM users in Taiwan between 1996 and 2001, and 62.5\% of people used TCM covered by the NHI during this period; this does not include folk medicine, which is not reimbursable by insurance. The widespread use of TCM in the Chinese population might not be surprising since TCM has been developed in China for more than 2000 years and the ancestors of most Taiwanese were immigrants from China from the $17^{\text {th }}$ century onwards. Many concepts of TCM, such as the balance of Qi-blood, the regulation of body constitution and the mixture of herbs and food, have been part of Chinese culture and life style. Other ancient cultures in the world have similar experiences with their traditional medicine [40-42]. In addition, Chinese people believe that Western medicine may react faster to the target but also causes more adverse side effects, while TCM reacts slowly but is subtle and safe $[16,43,44]$. Furthermore, the insurance coverage for TCM visits might also play a significant role [31]. Lee et al. reported that TCM outpatient use rate increased 1.75-fold from 1983 to 1988 because of the opening of labour insurance coverage in Taiwan [14]. These factors might all account for the high utilization of TCM.

It is interesting to know how health care was used when both Western medicine and TCM were available in Taiwan. Table 9 compares the use frequencies of outpatient visits between TCM and Western medicine. The results show that people visited Western medicine clinics more commonly than TCM clinics for their illnesses. Thus, Western medicine remains the mainstream of health care. TCM outpatient visits accounted for around $9 \%$ of all out-

Table 2: Age-specific usage frequency of traditional Chinese medicine (TCM) during the 6-year period from I996 to 200 I in Taiwan

\begin{tabular}{lccc}
\hline Age (years) & Number of total population* & Number of subjects using TCM (\%) & Number of TCM visits \\
\hline$\leq 10$ & $3,045,723$ & $376,098(12.3 \%)$ & $3,585,106$ \\
$1 \mathrm{I}-20$ & $3,384,508$ & $2,087,947(61.7 \%)$ & $18,557,467$ \\
$21-30$ & $3,821,115$ & $2,507,902(65.6 \%)$ & $22,970,206$ \\
$31-40$ & $3,802,330$ & $2,509,366(66.0 \%)$ & $30,974,575$ \\
$4 I-50$ & $3,538,240$ & $2,195,505(62.1 \%)$ & $29,908,451$ \\
$5 I-60$ & $2,051,260$ & $1,209,673(59.0 \%)$ & $16,445,165$ \\
$6 I-70$ & $1,445,062$ & $935,722(64.8 \%)$ & $13,234,416$ \\
$7 I-80$ & 989,984 & $580,621(58.6 \%)$ & $8,389,902$ \\
$\geq 8 I$ & 327,346 & $171,239(52.3 \%)$ & $2,084,788$
\end{tabular}

*Total population number was obtained from Department of Internal Affairs, Executive Yuan, Taiwan, and data at the end of $200 \mathrm{I}$ are presented. 


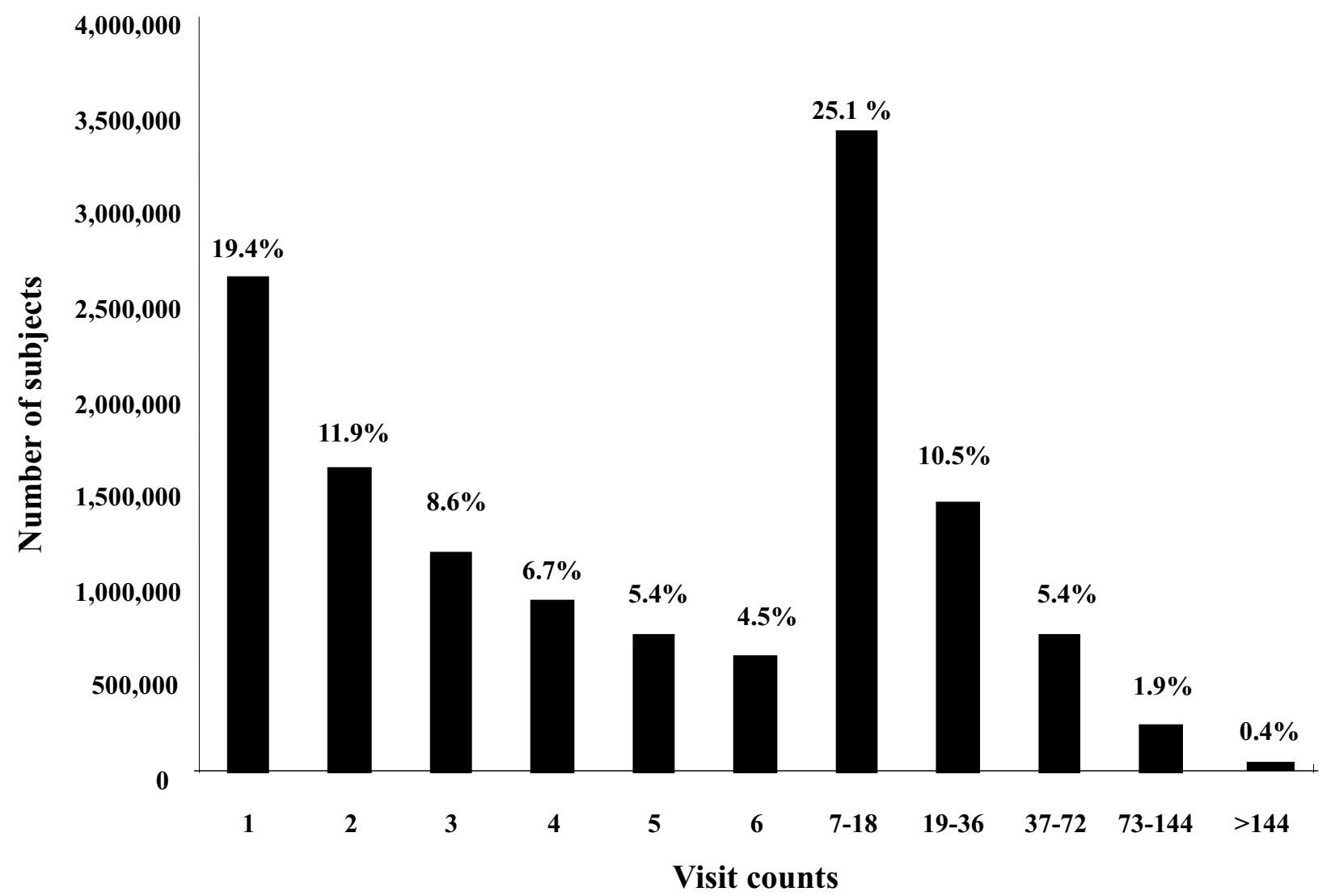

Figure I

Visits counts per patient using traditional Chinese medicine during the 6 years from 1996 to 200 I in Taiwan.

patient clinics. Notably, the average number of outpatient visits per person per year in both TCM and Western medicine increased from 1996 to 1999, but decreased in 2000 owing to the rise in co-payments for outpatient visit under the NHI, Taiwan from August 1999 [22].

Our finding that female use TCM more frequently than male, is consistent with previous reports from western countries $[31,32,45,46]$. Nevertheless, the reasons for this female predominance were not fully elucidated in previous reports. It was suggested that independent females, or females of good social status, had higher expectations of or belief in TCM in respect of postpartum conditions, menopause and chronic diseases [29-31], [47-49]. Our results show that disorders of menstruation and abnormal bleeding, noninflammatory disorders of female genital

Table 3: Service volume of traditional Chinese medicine (TCM) by facility type from 1996 to $200 \mathrm{I}$ in Taiwan

\begin{tabular}{|c|c|c|c|c|}
\hline Year & Public TCM hospital & Private TCM hospital & Private TCM clinics & Others* \\
\hline 1996 & $79,817(0.3 \%)$ & $4,561,521$ (I8.9\%) & $18,6 \mid 2,160(77.2 \%)$ & $841,054(3.5 \%)$ \\
\hline 1997 & $76,627(0.3 \%)$ & $3,845,787$ (I5.3\%) & $20,277,192(80.6 \%)$ & $970,467(3.9 \%)$ \\
\hline 1998 & $226,207(0.8 \%)$ & $3,407,727$ (12.8\%) & $21,963,148(82.4 \%)$ & $1,044,844(3.9 \%)$ \\
\hline 1999 & $267,511(1.0 \%)$ & $2,889,723(10.5 \%)$ & $23,024,679(84 \%)$ & $\mathrm{I}, 2 \mathrm{I} 6,682(4.4 \%)$ \\
\hline 2000 & $280,086(1.1 \%)$ & $2,320,469(8.8 \%)$ & $22,371,552(84.7 \%)$ & $\mathrm{I}, 454,646(5.5 \%)$ \\
\hline 2001 & $260,150(1.0 \%)$ & $\mathrm{I}, 766,232(6.7 \%)$ & $22,866,179(86.3 \%)$ & $1,599,806(6.0 \%)$ \\
\hline Total & $1,190,398(0.8 \%)$ & $18,79 \mid, 459(12.0 \%)$ & $129,114,910(82.6 \%)$ & $7,127,499(4.6 \%)$ \\
\hline
\end{tabular}

*Others: mostly western medicine hospitals with TCM section 
Table 4: The top 10 major disease categories for traditional Chinese medicine visits from I 996 to 200 I in Taiwan

\begin{tabular}{|c|c|c|c|}
\hline Major disease category & ICD-9-CM code & Number of visits & Percentage (\%) \\
\hline Diseases of the respiratory system & $460-519$ & $42,163,916$ & 27.0 \\
\hline Diseases of the musculoskeletal system and connective tissue & $710-739$ & $25,922,217$ & 16.6 \\
\hline Symptoms, signs and ill-defined conditions & $780-799$ & $22,273,597$ & 14.3 \\
\hline Injury and poisoning & 800-999 & $20,466,702$ & I3.1 \\
\hline Diseases of digestive system & $520-579$ & $19,854,039$ & 12.7 \\
\hline Diseases of the genitourinary system & $580-629$ & $11,269,623$ & 7.2 \\
\hline Diseases of the skin and subcutaneous tissue & $680-709$ & $5,086,736$ & 3.3 \\
\hline Diseases of the nervous system and sense organs & $320-389$ & $4,999,730$ & 3.2 \\
\hline Diseases of the circulatory system & $390-459$ & $3,|43,18|$ & 2.0 \\
\hline Endocrine, nutritional and metabolic disease and immune disorders & $240-279$ & $1,926,628$ & 1.2 \\
\hline
\end{tabular}

organs and inflammatory disorders of female pelvic organs were among the most common 40 disease groups for TCM visits, and this might in part account for the female predominance.

We found that the age distribution of TCM users peaked in the 30 s, followed by the 20 s and 40 s. More than $50 \%$ of people over 10 years old had used TCM at least once in the 6 years surveyed. Previous studies have also shown that middle aged females are the characteristic CAM users in western countries $[31,38,50,51]$. A survey of German university hospitals found that young age was one of the predictors for a positive attitude towards CAM [52]. These results may indicate that adults are more frequent users of TCM/CAM than children [12][19].

Our results revealed that most TCM visits were to private TCM clinics (82.6\%), followed by the private TCM hospitals $(12.0 \%)$. This is supported by Chi's report, which showed that most of the active Chinese medicine physicians $(82 \%)$ worked in personal practice clinics and only a small portion $(18 \%)$ worked in Chinese medicine hospitals [53]. Also, in the United States, CAM (acupuncture) is available on a limited basis in major teaching hospitals [54]; and almost $40 \%$ of all general practices in Western medicine in the United Kingdom offer some form of access to CAM [38]. Further studies are needed to evaluate the role of TCM in both clinical practice and academic research in teaching hospitals.

According to our results, the most common reasons for TCM visits were diseases of the respiratory, musculoskeletal, digestive, genitourinary systems, and symptoms, signs and ill-defined conditions. Other common problems and diseases of major human organ systems recognised in Western medicine were all listed in the top 41 diagnostic groups for TCM visits. Our results are consistent with previous reports from western and Asian countries that various problems or diseases of human organ systems recognised in Western medicine were indicated for CAM use, including problems of the musculoskeletal, respira- tory and digestive systems, neurological and psychological disorders, and general complaints [38,39,54-56]. It is also interesting to know for what kind of illnesses people in Taiwan seek help from TCM or Western medicine. Table 10 shows the top ten major disease categories for Western medicine outpatient visits from 1996 to 2001 in Taiwan, using 1:500 sampling from NHI files. The results show that all ten major disease categories were the same in both TCM and Western medicine, but the order from second to tenth was different. According to Linde, most people consult CAM for chronic pain resulting from chronic conditions or musculoskeletal system disorders [57]; and Chen et al. reported that more than $80 \%$ of indications for acupuncture visits in Taiwan were for musculoskeletal diseases [12]. These findings might explain the difference in the order of disease categories between TCM and Western medicine.

From the percentage distribution of diagnoses by age in our study, we found that for patients over the age of 20, conditions of major organ systems such as the musculoskeletal, nervous, circulatory and endocrine systems, as well as mental disorders, appeared more and more frequently in TCM visits, which might be a consequence of the aging process and the natural course of diseases. Evidently, respiratory conditions accounted for almost half of TCM visits in young people (aged under 20). Whether TCM has better efficacy and fewer side effects than Western medicine in treating conditions such as upper airway infection, asthma or allergy rhinitis deserves further evaluation $[58,59]$. We also found that TCM practitioners in clinics treated more injury conditions and symptoms, signs and ill-defined conditions than those in hospitals, while TCM practitioners in hospitals treated internal organ problems more than those in clinics [12]. Since the NHI program in Taiwan only covers outpatients, TCM practitioners in Chinese medicine sections in both Chinese and Western medical hospitals can deal with most ambulatory subjects, as in the clinics. However, in the hospitals, TCM doctors have to be trained strictly in either Chinese or Western medical school, unlike those in pri- 
Table 5: The 4 I most common diagnostic groups among 156,224,266 traditional Chinese medicine visits from I996 to 200 I in Taiwan

\begin{tabular}{|c|c|c|}
\hline Diseases diagnosis* & Number of visits & $\%$ \\
\hline Other symptoms signs and ill-defined conditions & $16,707,192$ & 10.7 \\
\hline Other diseases of the digestive system & $15,636,624$ & 10.0 \\
\hline Acute sinusitis & $13,790,219$ & 8.8 \\
\hline Other diseases of the respiratory system & $9,697,442$ & 6.2 \\
\hline Other dorsopathies & $9,593,900$ & 6.1 \\
\hline Other injuries & $8,265,712$ & 5.3 \\
\hline Derangements and other unspecified joint disorders & $6,219,704$ & 4.0 \\
\hline Asthma & $5,477,916$ & 3.5 \\
\hline Other superficial injury & $5,370,193$ & 3.4 \\
\hline Other acute respiratory infections & $4,74 I, 44 I$ & 3.0 \\
\hline Other rheumatism excluding back & $4,702,518$ & 3.0 \\
\hline Chronic sinusitis & $4,553,347$ & 2.9 \\
\hline Disorders of menstruation and abnormal bleeding & $4,437,200$ & 2.8 \\
\hline Other inflammatory conditions of skin and subcutaneous tissue & $3,729,128$ & 2.4 \\
\hline Contusions with intact skin surfaces & $3,230,326$ & 2.1 \\
\hline Non-inflammatory disorders of female genital organs & $2,704,322$ & 1.7 \\
\hline Ulcer of stomach and small intestine & $2,181,074$ & 1.4 \\
\hline Other disorders of the nervous system & $2,063,541$ & 1.3 \\
\hline Other disorders of the urinary system & $1,786,787$ & 1.1 \\
\hline Cough & $1,723,945$ & 1.1 \\
\hline Lumbago & $1,524,536$ & 1.0 \\
\hline Other sprains and strains & $1,417,778$ & 0.9 \\
\hline Allergic rhinitis & $1,266,224$ & 0.8 \\
\hline Other arthropathies and related disorders & $1,167,430$ & 0.7 \\
\hline Myalgia and myositis unspecified & $1,167,300$ & 0.7 \\
\hline Other mental disorders & $1,127,697$ & 0.7 \\
\hline Abnormal heart sounds & $1,115,173$ & 0.7 \\
\hline Acute bronchitis and bronchiolitis & $1,069,862$ & 0.7 \\
\hline Abdominal pain & $1,051,691$ & 0.7 \\
\hline Other diseases of the musculoskeletal system and connective tissue & $1,039,678$ & 0.7 \\
\hline Chronic and unspecified bronchitis & 998,966 & 0.6 \\
\hline Gastritis and duodenitis & 940,170 & 0.6 \\
\hline Inflammatory disorders of female pelvic organs & 871,451 & 0.6 \\
\hline Other diseases of the circulatory system & 844,021 & 0.5 \\
\hline Headache & 825,747 & 0.5 \\
\hline Other diseases of the ear and mastoid process & 817,140 & 0.5 \\
\hline Other disorders of the eye and adnexa & 758,455 & 0.5 \\
\hline Other infections and parasitic diseases & 746,719 & 0.5 \\
\hline Diabetes mellitus & 740,528 & 0.5 \\
\hline Other diseases of central nervous system & 731,867 & 0.5 \\
\hline
\end{tabular}

* Only diseases with use frequency of traditional Chinese medicine greater than $0.5 \%$ are presented. Diagnostic groups were categorized according to the reclassification of the primary International Classification of Diseases diagnostic codes for use with National Ambulatory Medical Care Survey and National Hospital Ambulatory Medical Care Survey data in the United States.

vate clinics [53], and may have more diagnostic information from Western medicine, which may explain the greater number of visits for internal organ system conditions. We also found that female subjects visited TCM clinics for diseases of the genitourinary system more frequently than males. Our results are consistent with Foxman's report that women are significantly more likely than men to experience urinary tract infection [60]. In addition, the female use of TCM predominate for the genitourinary system was due to the disorders of menstruation and abnormal bleeding, noninflammatory disorders of female genital organs and inflammatory disorders of female pelvic organs were among the most common 40 disease groups for TCM visits.

In view of the substantially increased use of TCM/CAM, we suggest that medical doctors should ask patients about their use of TCM/CAM when taking a medical history. Exploration of the use of TCM/CAM will enhance the understanding of these practices and help patients and doctors to communicate during medical care. As Eisenberg and his colleagues suggested a decade ago, medical schools should design the curriculum to include information about CAM and clinical social sciences [2]. Several 
Table 6: Percentage distribution of diseases categories for 156,224,266 traditional Chinese medicine visits by different age groups, 1996-200I, in Taiwan*

\begin{tabular}{|c|c|c|c|c|}
\hline \multirow[t]{2}{*}{ Major disease category } & \multicolumn{4}{|c|}{ Years of age } \\
\hline & $0-19$ & $20-39$ & $40-59$ & $>60$ \\
\hline Symptoms, signs, ill-defined conditions ${ }^{\dagger}$ & 13.2 & 13.2 & 15.0 & 16.2 \\
\hline Musculoskeletal system ${ }^{\dagger}$ & 5.3 & 15.5 & 21.0 & 25.4 \\
\hline Nervous system and sense organst ${ }^{\prime}$ & 1.1 & 2.6 & 4.2 & 5.6 \\
\hline Circulatory system ${ }^{\dagger}$ & 0.2 & I.I & 2.6 & 5.6 \\
\hline Endocrine and metabolic diseases ${ }^{\dagger}$ & 0.2 & 0.8 & 1.8 & 2.3 \\
\hline Mental disorderst & 0.2 & 0.7 & 1.0 & 1.0 \\
\hline Neoplasm ${ }^{\dagger}$ & 0.1 & 0.2 & 0.4 & 0.4 \\
\hline Digestive system & 9.5 & 12.9 & 13.9 & 13.6 \\
\hline Infectious and parasitic diseases & 0.3 & 0.6 & 0.5 & 0.4 \\
\hline Genitourinary system & 3.9 & 10.9 & 6.7 & 3.5 \\
\hline Respiratory system $\ddagger$ & 48.3 & 22.6 & 20.4 & 18.6 \\
\hline Skin and subcutaneous tissue & 4.0 & 4.3 & 2.2 & 1.7 \\
\hline Injury and poisoning & 14.0 & 15.3 & 11.9 & 8.5 \\
\hline
\end{tabular}

*5,836,65I (3.8\%) visits had more than one diagnosis. †Percentages increased with age. łPercentages decreased with age.

reports from western countries have concerned the need for CAM instruction to medical trainees and physicians $[61,62]$. Integration of Western medicine and TCM, in both medical education and clinical practice, should be initiated in countries where TCM and Western medication are widely used [53].

Our study has several limitations. First, NHI only reimburses Chinese herbal remedies in scientific granular or powder forms. Chinese herbal remedies in traditional herbal form such as Yin-Pian (prepared herbal medicine in small pieces ready for decoction, and medicine materials in crude slices) are not reimbursed and therefore are not included in our study. Secondly, our study did not include TCM visits provided by TCM clinics or hospitals that have no NHI contract, where patients need to pay entirely out-of-pocket. Finally, we did not include those Chinese herbal remedies obtained directly from traditional Chinese medicine pharmacies with or without pre- scriptions from licensed TCM doctors, nor did we include acupuncture performed by western-trained doctors. Thus, the use of TCM might have been underestimated in this study. Finally, without questionnaire surveys of patients, we were unable to ascertain the patients' beliefs, attitudes or inclinations towards TCM.

\section{Conclusion}

TCM is popular in the Chinese population. More than $60 \%$ of subjects used TCM at least once during the 6-year study period. TCM, like western medicine, was commonly used by the Chinese population for problems and diseases of major human organ systems. Chinese herbal remedies were the most common TCM modality in Taiwan. This study provides information about the use frequencies of TCM and disease categories treated by TCM, which should be useful for health policy makers and for those who consider the integration of Chinese and Western medicine.

Table 7: Number of visits and percentage distribution of diseases categories for traditional Chinese medicine visits by gender, 19962001 , in Taiwan

\begin{tabular}{lcc}
\hline Major disease category & Female & Male \\
\hline Diseases of the respiratory system & $22486766(24.7 \%)$ & $19229835(28.6 \%)$ \\
Diseases of the musculoskeletal system and connective tissue & $14591874(16.0 \%)$ & $10960835(16.3 \%)$ \\
Symptoms, signs and ill-defined conditions & $1311773 \mid(14.4 \%)$ & $8962408(13.4 \%)$ \\
Injury and poisoning & $10681063(11.7 \%)$ & $9549648(14.2 \%)$ \\
Diseases of the digestive system & $10358168(11.4 \%)$ & $9254229(13.8 \%)$ \\
Diseases of the genitourinary system & $9637077(10.6 \%)$ & $1470300(2.2 \%)$ \\
Diseases of the skin and subcutaneous tissue & $3012960(3.3 \%)$ & $2021566(3.0 \%)$ \\
Diseases of the nervous system and sense organs & $2987998(3.3 \%)$ & $19735 \mid 4(2.9 \%)$ \\
Diseases of the circulatory system & $1609018(1.8 \%)$ & $1496484(2.2 \%)$ \\
Endocrine, nutritional and metabolic diseases and immunological disorders & $934956(1.0 \%)$ & $954273(1.4 \%)$ \\
Total & 91204278 & $67 \mid 49765$
\end{tabular}


Table 8: Percentage distribution of diseases categories for 156,224,266 traditional Chinese medicine visits by location, $1996-2001$, in Taiwan*

\begin{tabular}{|c|c|c|}
\hline Major disease category & In Hospitals (\%) & In Clinics (\%) \\
\hline Respiratory system & 26.8 & 26.2 \\
\hline Musculoskeletal system & 20.3 & 16.2 \\
\hline Digestive system & 20.2 & 12.2 \\
\hline Genitourinary system & 12.0 & 6.9 \\
\hline Symptoms, signs, ill-defined conditions & $11.9+$ & $14.3^{\dagger}$ \\
\hline Nervous system and sense organs & 6.5 & 3.0 \\
\hline Circulatory system & 6.2 & 1.8 \\
\hline Skin and subcutaneous tissue & 5.7 & 3.1 \\
\hline Endocrine and metabolic diseases & 5.1 & 1.0 \\
\hline Injury and poisoning & $4.8^{\dagger}$ & $13.4 \dagger$ \\
\hline Mental disorders & 1.1 & 0.2 \\
\hline Neoplasm & 1.7 & 0.2 \\
\hline Infectious and parasitic diseases & 1.7 & 0.4 \\
\hline
\end{tabular}

*5,836,65I (3.8\%) visits had more than one diagnosis. tPercentage in Clinics is higher than in Hospitals.

Table 9: Comparison of the average number of outpatient visits per person per year between Traditional Chinese Medicine (TCM) and Western Medicine (WM) from 1996 to 2001 in Taiwan.

\begin{tabular}{|c|c|c|c|c|c|c|c|}
\hline Year & $\begin{array}{c}\text { Valid } \\
\text { beneficiaries }\end{array}$ & $\begin{array}{l}\text { Total TCM } \\
\text { visits }\end{array}$ & $\begin{array}{l}\text { TCM visits per } \\
\text { person }\end{array}$ & $\begin{array}{l}\% \text { change from } \\
\text { previous year }\end{array}$ & Total WM visits & $\begin{array}{l}\text { WM visits per } \\
\text { person }\end{array}$ & $\begin{array}{l}\% \text { change from } \\
\text { previous year }\end{array}$ \\
\hline 1996 & $20,04 I, 488$ & $24,094,552$ & 1.20 & & $221,566,817$ & 11.06 & \\
\hline 1997 & $20,492,317$ & $25,170,073$ & 1.23 & $2.17 \%$ & $241,309,995$ & 11.78 & $6.51 \%$ \\
\hline 1998 & $20,757,185$ & $26,641,926$ & 1.28 & $4.50 \%$ & $259,701,792$ & $12.5 \mid$ & $6.25 \%$ \\
\hline 1999 & $21,089,859$ & $27,398,595$ & 1.30 & $1.22 \%$ & $273,777,642$ & 12.98 & $3.76 \%$ \\
\hline 2000 & $21,400,826$ & $26,426,753$ & 1.23 & $-4.95 \%$ & $267,924,732$ & 12.52 & $-3.56 \%$ \\
\hline 2001 & $21,653,555$ & $26,492,367$ & 1.22 & $-0.92 \%$ & $267,4 \mid 2,756$ & 12.35 & $-1.36 \%$ \\
\hline
\end{tabular}

Table 10: Number and percentage distribution of visits to Western Medicine by major disease category from I996-200I in Taiwan.

\begin{tabular}{|c|c|c|c|}
\hline Major disease category & ICD-9-CM code range & Visits & $\%$ \\
\hline Diseases of the respiratory system & $460-519$ & $|, 347,67|$ & $45.9 \%$ \\
\hline Diseases of the digestive system & $520-579$ & 324,820 & $11.1 \%$ \\
\hline Diseases of the nervous system and sense organs & $320-389$ & 297,257 & $10.1 \%$ \\
\hline Diseases of the musculoskeletal system and connective tissue & $710-739$ & 251,625 & $8.6 \%$ \\
\hline Diseases of the circulatory system & $390-459$ & 228,051 & $7.8 \%$ \\
\hline Diseases of the genitourinary system & $580-629$ & 210,842 & $7.2 \%$ \\
\hline Diseases of the skin and subcutaneous tissue & $680-709$ & 198,619 & $6.8 \%$ \\
\hline Symptoms, signs, and ill-defined conditions & $780-799$ & 148,989 & $5.1 \%$ \\
\hline Endocrine, nutritional and metabolic diseases and immunological disorders & $240-279$ & $|38,77|$ & $4.7 \%$ \\
\hline Injury and poisoning & 800-999 & 97,843 & $3.3 \%$ \\
\hline Total visits & & $2,935,480$ & $100.0 \%$ \\
\hline
\end{tabular}

Data were obtained by 1:500 sampling from National Health Insurance files in Taiwan (see text for detail). All diagnoses at each claim were taken into consideration. 


\section{Abbreviations \\ TCM: traditional Chinese medicine}

CAM: complementary and alternative medicine

NHI: National Health Insurance

NHIRD: National Health Insurance Research Database

ICD-9-CM: International Classification of Diseases, Ninth Revision, Clinical Modification

\section{Competing interests}

The author(s) declare that they have no competing interests.

\section{Authors' contributions}

FPC conceived and carried out the study, performed the data analysis and drafted the manuscript. TJC and LFC participated in the design of the study and helped to perform the statistical analyses as well as to interpret findings. YCC, YYK and FJC performed the statistical analyses, helped to interpret findings and checked the grammar of the manuscript. SJH participated in the design and coordination of the study and helped to draft the manuscript. All authors read and approved the final manuscript.

\section{Acknowledgements}

This study is based in part on data from the National Health Insurance Research Database provided by the Bureau of National Health Insurance, Department of Health and managed by National Health Research Institutes in Taiwan. The interpretation and conclusions contained herein do not represent those of Bureau of National Health Insurance, Department of Health or National Health Research Institutes.

We would like to thank Dr. Maw-Shiou Jong and Mr. Yu Chen for assisting in data collection and manuscript editing.

\section{References}

I. anonymous: Complementary medicine is booming worldwide. BMJ 1996, 3 I3(7050): |3|-3.

2. Eisenberg DM, Kessler RC, Foster C, Norlock FE, Calkins DR, Delbanco TL: Unconventional medicine in the United States. Prevalence, costs, and patterns of use. N Engl J Med 1993, 328:246-252.

3. Ahmad AW: Determinants of complementary alternative medicine (CAM) use. Complement Ther Med 2004, I 2:99-I I I.

4. Barnes PM, Powell-Griner E, McFann K, Nahin RL: Complementary and alternative medicine use among adults: United States, 2002. Adv Data 2004, 343: I-20.

5. MacLennan AH, Wilson DH, Taylor AW: Prevalence and cost of alternative medicine in Australia. Lancet 1996, 347:569-573.

6. Boon H: Regulation of complementary/alternative medicine: a Canadian perspective. Complement Ther Med 2002, 10:14-19.

7. Reilly D: Comments on complementary and alternative medicine in Europe. J Altern Complem Med 200I, 7(SuppI I):s23-3I.

8. Burg MA, Hatch RL, Neims AH: Lifetime use of alternative therapy: A study of Florida residents. South Med I I998, 91:||26-||3|.

9. Eskinazi DP: Factors that shape alternative medicine. JAMA 1998, 280:1621-1623.

10. Low R: Acupuncture: Technique for successful point selection Oxford: Butterworth-Heinemann; 200I:I-I4.
II. Wu Y, Fisher W, Fratkin J: Practical Therapeutics of Traditional Chinese Medicine Paradigm Publications; 1997.

12. Chen FP, Kung YY, Chen TJ, Hwang SJ: Demographics and patterns of acupuncture use in the Chinese population: The Taiwan experience. J Altern Complem Med 2006, I 2:379-387.

13. Lim MK, Sadarangani P, Chan HL, Heng JY: Complementary and alternative medicine use in multiracial Singapore. Complement Thera Med 2005, 13:16-24.

14. Lee JL, Chi C, Lai JS: A critical review of the policy research on Chinese medicine in Taiwan, 1981-1994. Public Health 1994, 21:97-107. (in Chinese)

15. Wu HC, Lai JN, Yeh CH: Health care policy on traditional Chinese medicine in Taiwan. Taipei City Med J 2005, 2:879-894.

16. Chen CY, Chang SK, Chi C, Chen SC, Lee JL, Lai JS: The factors which influence people in the utilization of Chinese medicine. Chin Med Coll J 1999, 8:77-88. (in Chinese)

17. Chi C: Integrating traditional medicine into modern health care systems: examine the role of Chinese medicine in Taiwan. Soc Sci Med 1994, 39:307-32I.

18. Chi C, Lee JL, Lai JS, Chen SC, Chen CY, Chan SK: The demand and supply of Chinese medicine in modern health care system. In American Public Health Association II 9th Annual Meeting, Asia American Scientific Sessions, Wasions, Washington DC; 1992.

19. Lee $\mathrm{CH}$, Chou YJ, Chen LS, Chang HJ: Utilization of ambulatory Chinese medical services under the National health Insurance in Taiwan. Taiwan J Public Health 2004, 23:100-107. (in Chinese)

20. Lee JC, Chi C, Lai JS: The effects of time, income and price on the demand for Chinese medicine ambulatorycare. Chin J Public Health (Taipei) 1995, 14:470-476. (in Chinese)

21. Cheng SH, Chiang TL: The effect of universal health insurance on health care utilization in Taiwan: results from a natural experiment. JAMA 1997, 278:89-93.

22. Health and National Health Insurance Annual Statistics Information Services [http://www.doh.gov.tw/statisticl
[ index.htm]

23. Cheng TM: Taiwan's new national health insurance program: genesis and experience so far. Health Aff (Millwood) 2003, 22:61-76.

24. An internet resource guide to traditional Chinese medicine in Taiwan. Committee on Chinese Medicine and Pharmacy, Department of Health, Executive Yuan, R.O.C. Taipei 2004. (in Chinese)

25. Koo J, Desai R: Traditional Chinese medicine in dermatology. Dermatol Ther 2003, 16:98-105.

26. Liu JY, Chen TJ, Hwang S): Concomitant prescription of nonsteroidal anti-inflammatory drugs and antacids in the outpatient setting of a medical center in Taiwan: A prescription database study. Eur J Clin Pharmacol 200I, 57:505-508.

27. Chen TJ, Chou LF, Hwang SJ: Application of data-mining technique to analyze the coprescription patterns for antacids in Taiwan. Clin Ther 2003, 25:2453-2463.

28. Chen TJ, Chou LF, Hwang SJ: Patterns of ambulatory care utilization in Taiwan. BMC Health Serv Res 2006, 6:54.

29. US Department of Health and Human Services from the Centers for Disease control and Prevention/National Center for Health Statistics: Ambulatory care visits to physician offices, hospital outpatient departments, and emergency departments: United States, 1997. Vital and Health Statistics 1999. Series 13, No. 143

30. Cleary-Guida MB, Okvat HA, Oz MC, Ting W: A regional survey of health insurance coverage for complementary and alternative medicine: Current status and future ramifications. J Altern Complem Med 200I, 7:269-273.

31. Wolsko PM, Eisenberg DM, Davis RB, Ettner SL, Philips RS: Insurance coverage, medical conditions, and visits to alternative medicine providers- results of a national survey. Arch Intern Med 2002, 162:28I-287.

32. Eisenberg DM, Davis RB, Ettner SL, Appel S, Wilkey S, Van Rompay $M$, Kessler RC: Trends in alternative medicine use in the United States, 1990-1997: results of a follow-up national survey. JAMA 1998, 280:1569-1575.

33. Wolsko P, Ware L, Kutner J, Lin CT, Albertson G, Cyran L, Schilling $\mathrm{L}$, Anderson RJ: Alternative/complementary Medicine: Wider usage than generally appreciated. J Altern Complem Med 2000, 6:321-326. 
34. Tindle HA, Davis RB, Phillips RS, Eisenberg DM: Trends in use of complementary and alternative medicine by US adults: | 997-2002. Altern Ther Health M 2005, I I:42-49.

35. Hong C: Complementary and alternative medicine in Korea: current status and future prospects. J Altern Complem Med 200 I, 7(Suppl I):s33-40.

36. Yamashita H, Tsukayama H, Sugishita C: Popularity of complementary and alternative medicine in Japan: a telephone survey. Complement Ther Med 2002, 10:84-93.

37. Napadow V, Kaptchuk T]: Patient Characteristics for outpatient acupuncture in Beijing, China. J Altern Complem Med 2004, 10:565-572.

38. Zollman C, Vickers A: ABC of complementary medicine: Users and practitioners of complementary medicine. BMJ 1999 , 31 9:836-838.

39. US Department of Health and Human Services from the Centers for Disease control and Prevention/National Center for Health Statistics: Complementary and alternative medicine use among adults: United States, 2002. Vital and Health Statistics 2004, 343: I-20.

40. Engebreston J: Culture and complementary therapies. Complement Ther Nurs Midwifery 2002, 8: I77-184.

4I. Oumeish OY: The philosophical, culture, and historical aspects of complementary, alternative, unconventional and integrative medicine in the old world. Arch Dermatol 1998, I 34: |373-I386.

42. Furnham A, Forey J: The attitudes, behaviors and beliefs of patients of conventional vs. complementary (alternative) medicine. J Clin Psychol 1994, 50:458-69.

43. Kang JT, Lee KF, Chen CF, Chou P: Factors related to the choice between traditional Chinese medicine and modern western medicine. J Formos Med Assoc 1994, 93(SuppI I):s49-55.

44. Long L, Huntley A, Ernst E: Which complementary and alternative therapies benefit which conditions? A survey of the opinions of $\mathbf{2 2 3}$ professional organizations. Complement Ther Med 200I, 9:178-185

45. Ma GX: Between two worlds: the use of traditional and Western health services by Chinese immigrants. I Commun Health 1999, 24:421-437.

46. Druss BG, Rosenheck RA: Association between use of unconventional therapies and conventional medical services. JAMA 1999, 282:65 I-656.

47. Paramore LC: Use of alternative therapies: Estimates from the I 994 Robert Wood Johnson Foundation National Access to Care Survey. J Pain Symptom Manag 1997, I 3:83-89.

48. Chou P: Factors related to utilization of traditional Chinese medicine in Taiwan. Chin Med J (Taipei) 200I, 64:191-202.

49. Chan MF, Mok E, Wong YS, Tong TF, Day MC, Tang CK, Wong DH: Attitudes of Hong Kong Chinese to traditional Chinese medicine and Western medicine: survey and cluster analysis. Complement Ther Med 2003, I I:103-109.

50. Astin JA: Why patients use alternative medicine: results of a national survey. JAMA 1998, 279: I548-I553.

51. Hedderson MM, Patterson RE, Neuhouser ML, Schwartz SM, Bowen DJ, Standish LJ, Marshall LM: Sex differences in motives for use of complementary and alternative medicine among cancer patients. Altern Ther Health M 2004, I 0:58-64.

52. Huber R, Koch D, Beiser I, Zschocke I, Luedtke R: Experience and attitudes towards CAM- a survey of internal and psychosomatic patients in a German university hospital. Altern Ther Health M 2004, 10:32-36.

53. Chi C, Lee JL, Lai JS, Chen CY, Chang SK, Chen SC: The practice of Chinese medicine in Taiwan. Soc Sci Med 1996, 43: I329-1348.

54. Blais R, Maiga A, Aboubacar A: How different users and nonusers of alternative medicine. Can I Public Health 1997, 88: $159-162$.

55. Millar WJ: Use of alternative health care practitioners by Canadians. Can J Public Health 1997, 88: I54-I58.

56. Hagen LE, Schneider R, Stephens D, Modrusan D, Feldman BM: Use of complementary and alternative medicine by pediatric rheumatology patients. Arth Rheum 2003, 49:3-6

57. Linde K, Vickers A, Hondras M, Riet G, Saller R, Melchart D: Systematic reviews of complementary therapies - an annotated bibliography. BMC Complement Altern Med 200I, I:3-I2.

58. Andrews L, Lokuge S, Sawyer M, Lillywhite L, Kennedy D, Martin J: The use of alternative therapies by children with asthma: a brief report. J Paediatr Child Health 1998, 34:| 3 |-4.
59. Kung YY, Chen YC, Hwang SJ, Chen TJ, Chen FP: The prescriptions frequencies and patterns of Chinese herbal medicine for allergic rhinitis in Taiwan. Allergy 2006, 6 I:1316-1318.

60. Focman B: Epidemiology of urinary tract infections: incidence, morbidity, and economic costs. Am J Med 2002, I I3(Suppl IA):5S-13S

6I. Hui KK, Zylowska L, Hui EK, Yu JL, Li JJ: Introducing integrative east-west medicine to medical students and residents. J Altern Complem Med 2002, 8:507-5I 5.

62. Giordano J, Garcia MK, Strickland G: Integrating Chinese traditional medicine into a US public health paradigm. J Altern Complem Med 2004, 10:706-7I0.

\section{Pre-publication history}

The pre-publication history for this paper can be accessed here:

http://www.biomedcentral.com/1472-6963/7/26/prepub
Publish with Biomed Central and every scientist can read your work free of charge

"BioMed Central will be the most significant development for disseminating the results of biomedical research in our lifetime. "

Sir Paul Nurse, Cancer Research UK

Your research papers will be:

- available free of charge to the entire biomedical community

- peer reviewed and published immediately upon acceptance

- cited in PubMed and archived on PubMed Central

- yours - you keep the copyright
BioMedcentral 